\title{
Zygomatic Mastoiditis with Extracranial Complications: An Extremely Rare Cause of Cheek Swelling
}

\author{
Woongsang Sunwoo, Dong Woo Nam, and Young Ho Kim \\ Department of Otorhinolaryngology-Head and Neck Surgery, Seoul National University Boramae Medical Center, \\ Seoul National University College of Medicine, Seoul, Korea
}

\author{
볼 부종의 드문 원인: 합병증을 동반한 광대벼 유양돌기염 \\ 선우웅상 · 남동우 · 김영호 \\ 서울대학교 의과대학 보라매병원 이비인후과학교실
}

\author{
Received July 8, 2016 \\ Revised October 4, 2016 \\ Accepted October 14, 2016 \\ Address for correspondence \\ Young Ho Kim, MD, PhD \\ Department of Otorhinolaryngology- \\ Head and Neck Surgery, \\ Seoul National University \\ College of Medicine, \\ Seoul National University \\ Boramae Medical Center, \\ 20 Boramae-ro 5-gil, Dongjak-gu, \\ Seoul 07061, Korea \\ Tel $+82-2-870-2442$ \\ Fax $+82-2-870-3863$ \\ E-mail yhkiment@gmail.com
}

Zygomatic mastoiditis is an extremely rare cause of an inflamed, swollen cheek. We encountered a 10-year-old girl with left preauricular swelling, pain, and mild trismus. Temporal bone computed tomography revealed a zygomatic root abscess with bone defects and a scanty amount of soft tissue lesion in Prussak's space. After antibiotic therapy for 2 weeks, her pain subsided, but the swelling persisted. All inflamed air cells, including the lesion in the zygomatic root, were eradicated. The swelling subsided after the surgery. The patient has not experienced any postoperative complications or shown any evidence of relapse for more than 1 year.

Korean J Otorhinolaryngol-Head Neck Surg 2018;61(2):110-3

Key Words Complications $\cdot$ Mastoiditis $\cdot$ Zygoma $\cdot$ Zygomatic process.

\section{Introduction}

Acute mastoiditis has been rarely reported since the advent of antibiotics. The so-called zygomatic mastoiditis is caused by the spread of suppurative otomastoiditis into the zygomatic root via air cells. Zygomatic mastoiditis was quite commonly reported until the 1920s and 1930s. ${ }^{1)}$ However, this form of mastoiditis has been rarely reported by contemporary otologists. ${ }^{2,3)}$ Because of its rareness, most clinicians might be unfamiliar with it, and the ignorance about this disease could lead to delayed diagnosis and treatment.

Here, we report a case of zygomatic mastoiditis in a 10-year-

This is an Open Access article distributed under the terms of the Creative Commons Attribution Non-Commercial License (http://creativecommons.org/licenses/by-nc/4.0) which permits unrestricted non-commercial use, distribution, and reproduction in any medium, provided the original work is properly cited. old girl who presented with preauricular swelling with tenderness and underwent surgical treatment to eradicate the lesion.

\section{Case}

A 10-year-old girl visited the department of pediatrics with a 2-day history of pain and swelling in the left temporomandibular joint area. She had no otalgia, otorrhea, hearing loss, and fever. A physical examination revealed redness, swelling, and tenderness on her left zygomatic process. To exclude the possibility of mumps, which is characterized by a swollen cheek, we performed laboratory examinations for antibody to mumps and serum amylase. The test results were negative, and hence, a diagnosis of mumps was ruled out. 

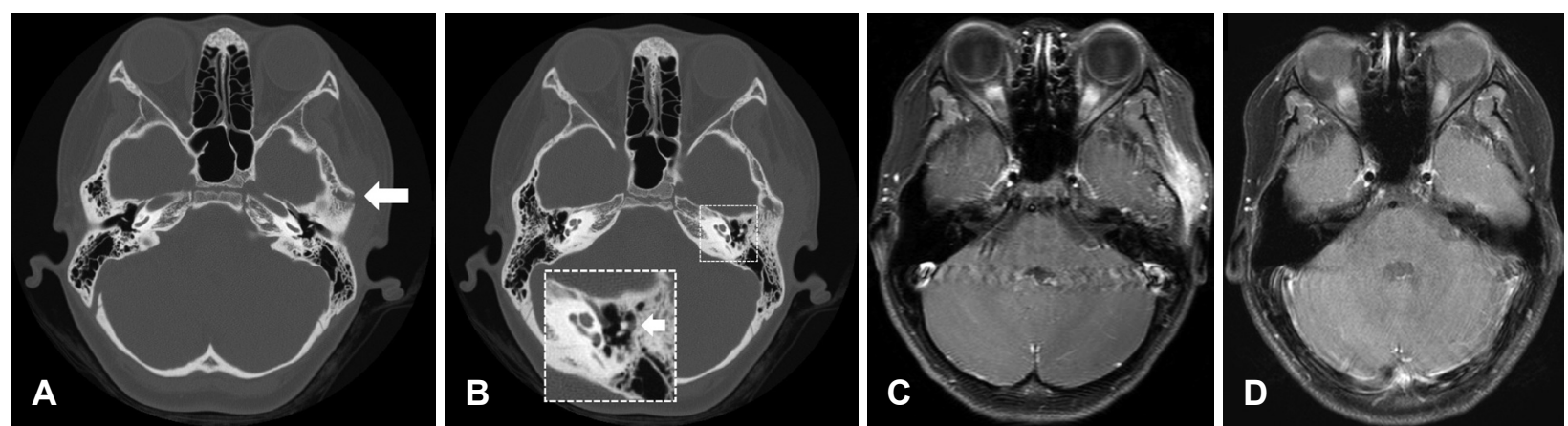

Fig. 1. Preoperative and postoperative radiologic findings. Axial temporal bone computed tomography (TBCT) images show cortical bony destruction around the root of the left zygomatic process (arrow, A) and scanty amount of soft tissue lesion in Prussak's space (arrow, B). Gadolinium-enhanced T1-weighted paranasal sinus magnetic resonance image (PNS-MRI) shows an inflammatory lesion around the left zygomatic process (C). Postoperative PNS-MRI shows no evidence of recurrence at 16 months after the surgery (D).

Facial ultrasonography revealed an 8.5-mm hypoechoic lesion on the left zygomatic process. She was then referred to the department of otolaryngology for further management.

Otological examinations revealed no finding of otitis media. Otoendoscopic examination of the tympanic membranes and audiograms showed normal findings. Moreover, there were no specific findings in the nasal cavity, oral cavity, and larynx. She had no systemic symptoms such as fever or chill. Nevertheless, she was admitted for further evaluation and antibiotic therapy. For differential diagnosis, temporal bone computed tomography (TBCT) and paranasal sinus magnetic resonance imaging (PNS-MRI) were performed. TBCT revealed inflammatory findings around the root of the left zygoma with cortical bone destruction and scanty amount of soft tissue lesion in Prussak's space (Fig. 1A and B). PNS-MRI revealed soft tissue swelling with enhancement around the left zygomatic process, which suggested myositis and cellulitis (Fig. 1C). Fine-needle aspiration cytology showed no malignant cells, and the microorganism culture study revealed no growth of bacteria. On the basis of these findings, she was diagnosed with zygomatic mastoiditis with extracranial complications. Initially, antibiotics were used to avoid further complications by zygomatic abscess with unknown origin. However, microbiology information was not available for selection of proper antibiotics. We selected the broad-spectrum antibiotics which should cover the invasive strains of bacteria and cross the blood-brain barrier. After intravenous antibiotic therapy (ceftriaxone sodium) during hospitalization (11 days), her pain and tenderness improved. Moreover, the Creactive protein level and erythrocyte sedimentation rate normalized. However, the preauricular swelling persisted and ultrasonography revealed an increase in the size and extent of the hypoechoic lesion. Previous studies reported that anaero- bic infection can present like this and increase the risk of developing osteomyelistis. ${ }^{4,5)}$ Therefore, surgical intervention was planned for obtaining both aerobic and anaerobic cultures, draining the abscess, and removing the infected air cells in the zygomatic process.

An oblique skin incision was made on the suprazygomatic area to prevent facial nerve injury (Fig. 2A). We approached the zygomatic process of the temporal bone under the temporal muscle without damaging the facial nerve (Fig. 2B). Purulent discharge occurred upon approaching the zygomatic bone erosion area; the pus was sampled and a microorganism culture study was performed. Inside the bony defect, inflammatory granulation tissue was found, and it was sampled for culture study and biopsy. All inflamed air cells, including the lesion in the zygomatic root, were eradicated (Fig. 2C). Because the size of the open cavity was small enough, obliteration was not performed. Periosteal flap, subcutaneous tissue and skin were sutured layer by layer. Immediate postoperative facial depression or deformity was not shown. There was no postoperative evidence of facial weakness.

The pus and granulation tissue cultures tested negative for microorganisms. Histopathological examination showed that the inflamed granulation and bone tissues had necrosis and fibrosis. The final pathological diagnosis was consistent with benign granulomatous inflammatory lesion. When compared to the preoperative facial finding, postoperative findings showed the disappearance of the swelling on the left zygomatic arch (Fig. 2D and E). She was discharged from the hospital without any complication.

The patient has shown no evidence of recurrence for more than 1 year after the surgery. Complete improvement of the lesion was confirmed by postoperative PNS-MRI performed 16 months after the surgery (Fig. 1D). 

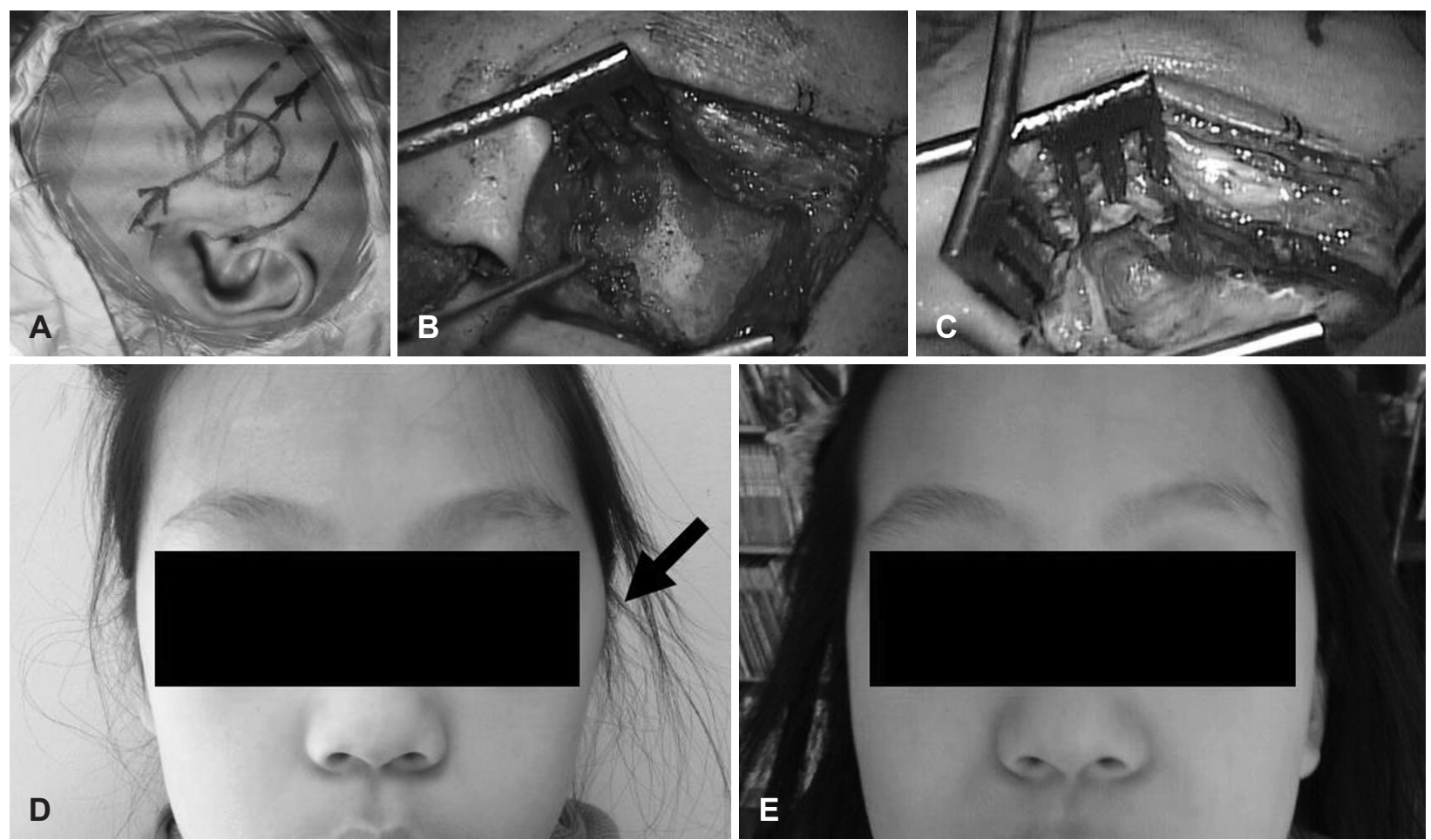

Fig. 2. Clinical photographs. Expected course of facial nerves is marked preoperatively, and a suprazygomatic oblique skin incision is planned (A). We approach the left zygomatic process of the temporal bone under the temporal muscle without causing facial nerve damage (B). Infected bone tissue is drilled out and all air cells around the zygomatic process root area are eradicated (C). Preoperative presentation of the patient shows moderate swelling on the left zygomatic arch (arrow, D). At 16 months after the first surgery, complete improvement and no evidence of recurrence is observed $(E)$.

\section{Discussion}

The individual pneumatization of the temporal bone varies considerably during extension. In a few cases, it extends to the root of the zygomatic arch. Sometimes, as seen in the present case, air cells may extend to the articular tubercle of the temporal bone. In 1985, Tyndall and Matteson ${ }^{6)}$ used the term 'pneumatization of the articular tubercle of the temporal bone' to describe the extended air cells in the zygomatic process of the temporal bone, considering it a normal anatomic variation. This asymptomatic radiolucency with a cystic appearance noted on panoramic radiographs-the commonly employed imaging modality in dental clinics-is called a 'zygomatic air cell defect (ZACD),' and it may be confused with a pathologic condition. The prevalence of ZACD on panoramic radiographs was reported to be $1.82 \%{ }^{7)}$ These air cells could serve as potential pathways for the spread of infection. Studies had documented zygomatic abscesses until about 70 years ago, and these studies introduced the term 'zygomatic mastoiditis.',

Zygomatic mastoiditis is usually caused by suppurative otomastoiditis. The path of the infection from the mastoid to the zygoma is generally along a preformed track of cells. ${ }^{1)}$ However, sometimes there is no direct communication between the mastoid and zygoma. Three possible routes have been suggested. First, the infection passes directly from the attic vault to the diploe of the squama. Second, the petrotympanic fissure, also known as the 'glaserian fissure,' can be a possible pathway because there are communications through the fissure to the infratemporal fossa. Third, the persistent petrosquamous sinus (PSS) has been suggested as another pathway because the PSS arises from the dorsolateral portion of the transverse sinus, courses over the lateral superior surface of the petrous bone, and drains into the retromandibular vein via the foramen retroarticulare. ${ }^{8)}$ In the present case, we could observe the air cell tract from the mastoid to the zygoma. However, TBCT revealed a clear mastoid and mesotympanum, and only a small space in the anterior epitympanum at the attic vault was opacified (Fig. 1C). In consideration of these findings, the more probable path of infection would have been the direct passage from the attic vault or the glaserian fissure, rather than the direct spread of infection from the mastoid. Moreover, the patient showed no visible persistent PSS.

In the present case, the patient had no otalgia, otorrhea, hear- 
ing loss, and fever. Swelling, pain, and focal tenderness on the zygomatic process area were the chief complaints, and there was no typical sign or symptom of acute otitis media or conventional acute mastoiditis. Therefore, because of these atypical presentations, we first considered the possibility of a local skin infection such as cellulitis. Moreover, TBCT and PNS-MRI revealed no remarkable findings in the mastoid and tympanum. However, abscess formation with cortical bony destruction around the root of the left zygomatic process on TBCT enabled the diagnosis of zygomatic mastoiditis with extracranial complications. The confusing or masking feature of mastoiditis is generally related to multiple-antibiotic therapy or a predisposing immunosuppressed state. ${ }^{9)}$ However, our patient did not have a past medical history of these conditions.

Previous studies have shown that the common aerobes associated with zygomatic mastoiditis are group A beta-hemolytic streptococci. ${ }^{1)}$ Anaerobes such as Bacteroides disiens have also been isolated in other studies. ${ }^{10)}$ When Bacteroides disiens is cultured, the risk of developing osteomyelitis is increased. However, preoperative, and even intraoperative, bacterial culture studies showed no growth of microorganisms, probably because of the administration of antibiotic therapy (ceftriaxone sodium) in this case.

However, antibiotic therapy may be one of important options in unknown inflammatory diseases. Culture results and the sensitivity of the organism ultimately govern selection of medications. When complications such as osteomyelitis were suspected one week after medical treatment, further surgery was accepted to be appropriate. ${ }^{10,11)}$ Thus a case could be made for staged intervention, treating the acute inflammation with adequate intravenous antibiotics, and performing surgical procedure such as an abscess drainage if complications are suspected.

For successful surgical removal of the inflammatory tissue in the zygomatic process, safe preservation of the facial nerve branches is required. To prevent facial nerve damage, we marked the expected course of the facial nerve preoperatively and approached the zygomatic process from under the temporal muscle by using a suprazygomatic oblique skin incision behind the lesion. The lesion in the zygomatic process root could be eradicated completely through this approach.

We report a rare case of zygomatic mastoiditis with extracranial complications. Unusual manifestations and signs in zygomatic mastoiditis cases make the diagnosis difficult. As shown in this case, inflammation and abscess on an atypical bony area can develop even without any predisposing factors. TBCT is helpful and essential to arrive at an accurate diagnosis and surgical decision in such cases. Otolaryngologists should pay attention to the possibility of this disease in the clinical setting, and should perform complete eradication of the lesion to avoid recurrence.

\section{REFERENCES}

1) Reading P. Zygomatic mastoiditis. Lancet 1947;1(6456):702-4.

2) Gurgel RK, Woodson EA, Lenkowski PW, Gubbels SP, Hansen MR. Zygomatic root abscess: a rare complication of otitis media. Otol Neurotol 2010;31(5):856-7.

3) Tsai CJ, Guo YC, Tsai TL, Shiao AS. Zygomatic abscess complicating a huge mastoid cholesteatoma with intact eardrum. Otolaryngol Head Neck Surg 2003;128(3):436-8.

4) Raff MJ, Melo JC. Anaerobic osteomyelitis. Medicine (Baltimore) 1978;57(1):83-103.

5) Moloy PJ. Anaerobic mastoiditis: a report of two cases with complications. Laryngoscope 1982;92(11):1311-5.

6) Tyndall DA, Matteson SR. Radiographic appearance and population distribution of the pneumatized articular eminence of the temporal bone. J Oral Maxillofac Surg 1985;43(7):493-7.

7) Patil K, Mahima VG, Malleshi SN, Srikanth HS. Prevalence of zygomatic air cell defect in adults--a retrospective panoramic radiographic analysis. Eur J Radiol 2012;81(5):957-9.

8) Watson-Williams E. Mastoid disease without otorrhoea. Br Med J 1929;2(3597):1099-101.

9) Tovi F, Gatot A, Lantsberg S. [Masked mastoiditis]. Harefuah 1993; 125(3-4):82-5, 127.

10) Warnaar A, Snoep G, Stals FS. A swollen cheek, an unusual course of acute mastoiditis. Int J Pediatr Otorhinolaryngol 1989;17(2):17983.

11) Walenkamp G. Antibiotica in de orthopedie. Geneesm Bull, Jaargang 1986;20:35-42. 